mammograms are caused by technical faults, a third are radiologically occult, and a third are fast-growing tumours not yet detectable at screening. ${ }^{10}$ By following a number of strict rules, we are attempting to reduce the number of falsenegative cases to the theoretical minimum. ${ }^{11}$

We thank S. Veling, H. Straatman, H. Coopmans, Ms I. vd Steen (Department of Social Medicine), and K. Jannink (Department of Radiology) for data analysis, processing, and gathernng; $F$. de Groot for his comments; and the Carcinoma Werkgroep Arnhem who made available to us data on breast cancer incidence in Arnhem, the Central Bureau for Statistics, and the local authorities. This work was supported by the Praeventiefonds and the Ministry of Health.

Correspondence should be addressed to A. L. M. V., Department of Social Medicine, Katholieke Universiteit Nijmegen, Verlengde Groenestraat 75 , 6525 EJ Nipmegen, The Netherlands.

\title{
REFERENCES
}

1 Shapiro S, Strax P, Venet L. Periodic breast cancer screening in reducing mortality from breast cancer fAMA 1971, 215: 1777-85.

2. Shapiro S, Venet W, Strax PH, Venet L, Roeser R. Ten-to-fourteen-year effect of screening on breast cancer mortality. I Natl Cancer Inst 1982, 69: 349-55

3 Habbema JDF, Putten DJ van, Lubbe JThN, Maas PJ van der, Oortmarssen GJ van. Geen verschillen in resultaten tussen vrouwen onder en boven de 50 aar bil bevolkıngsonderzoek op borstkanker. T Soc Gezondhetdsz 1983, 61: 694-97

4. Hendriks JHCL. Population screening for breast cancer by means of mammography in Nimegen 1975-1980. Ph D Thesis. University of Nimmegen, the Netherlands, 1982.

5. Clarke EA, Anderson TW'. Does screening by "Pap" smears help prevent cervical cancer? Lancet $1979 ; 1 \cdot 1-4$

6 Morrison AS. Case definition in case-control studies of the efficacy of screening. $A m 7$ Epidemol 1982, 115: 6-8

7 Weiss NS Control definition in case-control studies of the efficacy of screening and diagnostic testing. Am 7 Epidemol 1983; 118: 457-60

8. Breslow NE, Day NE. Classical methods of analysis of matched data. In Davis W, ed Statistical methods in cancer research. IARC Scientific publication no 32. Lyon: IARC, $1980.170-72$.

9 Prorok PC, Hankey BF, Bundy BN. Concepts and problems in the evaluation of screening programs 7 Chron Dis 1981, 34: 159-71.

0 Holland R, Mravunac M, Hendriks JHCL, Bekker BV. So-called interval cancers of the breast; pathologic and radiologic analysıs of 64 cases Cancer 1982; 49: 2527-33.

11. Holland R, Hendriks JHCL, Mravunac M. Mammographtcally occult breast cancer, a pathologic and radiologic study Cancer 1983, 52:1810-19.

\section{EVALUATION OF SCREENING FOR BREAST CANCER IN A NON-RANDOMISED STUDY (THE DOM PROJECT) BY MEANS OF A CASE-CONTROL STUDY}

\section{H. J. A. Collette}

\section{J. J. ROMBACH}

N. E. DAY

F. DE WAARD

Preventicon, Utrecht, The Netherlands; and International Agency for Research on Cancer, Lyon, France

Summary In 1974 a non-randomised study of the effect of mass screening by physical examination and xeromammography on mortality from breast cancer was started. Of the 20555 eligible women in the city of Utrecht born between 1911 and 1925 (aged 50-64 at the start of the study), 14796 attended for screening. Four rounds of screening were carried out. The relative risk of dying from breast cancer among women ever screened compared with women never screened was 0.30 (95\% confidence interval $0 \cdot 13-0 \cdot 70$ ).

\section{INTRODUCTION}

AFTER the publication of the results of the Health Insurance Plan (HIP) study on mortality from breast cancer in postmenopausal women, ${ }^{1}$ we decided to obtain more insight into the natural history of breast cancer in such women and to confirm whether a screening programme in older women would affect mortality from this disorder. In 1974 a population-based, non-randomised study of women in the city of Utrecht (the DOM project) was initiated. ${ }^{2}$ The population consisted of women born between 1911 and 1925 who were 50-64 years of age at the start of the project. A comparison of mortality in Utrecht with that of other cities in the Netherlands with similar population characteristics and degrees of health care was postponed owing to the extended period of study required, since in such a comparison deaths of women whose breast cancer was diagnosed before the start of the project would also be included.

A matched case-control study was used to investigate whether there is any association between the risk of mortality from breast cancer and participation in a population-based screening programme. This approach has been recommended as an epidemiological method to evaluate nonrandomised designs. ${ }^{3-6}$

\section{SUBJECTS AND METHODS}

Of 20555 eligible women in Utrecht, 14796 (72\%) women attended for screening. Screening, which consisted of a clinical examination and xeromammography, was carried out at the first visit and subsequently after 12, 18, and 24 months.

All breast cancer patients, irrespective of age or method of diagnosis, diagnosed from 1973 onwards were included in a breast cancer registry attached to the DOM project. Follow-up data on all women with breast cancer, born between 1911 and 1925 , were regularly updated. The names and dates of birth of all Utrecht residents who died from breast cancer were supplied, under strict confidentiality, by the Chief Medical Office of Health. Dates of diagnosis in these women were checked, first against the cancer registry, and with other sources, such as the general practitioners, if the name was not present in the registry.

In this study a case is defined as a breast cancer death in a woman born between 1911 and 1925, diagnosis and death occurring after the screening project started. With the help of the local authorities three controls for each case were selected at random. Criteria for eligibility as a control were that the woman should have lived in Utrecht when the case died and have the same year of birth as the case. Age matching was done because of the positive relation between death from breast cancer and age and the negative relation between the percentage attending for screening and age. For both the case and the corresponding controls the screening history was taken for the time up to and including the date of diagnosis of the case (a "restricted period", to be distinguished from the period of the total screening programme).

Table I gives the total number of deaths from breast cancer and from the birth cohort under study (1911-1925) in the city of Utrecht for the period 1973-1981. The last group is divided into cases diagnosed before and after the start of the DOM project. The 10 misclassified deaths were removed from the study. Accordingly, 46 cases were included. There is no reason to assume that misclassifications were made in one direction only and checks are being made of this question.

TABLE I-DEATHS FROM BREAST CANCER IN UTRECHT

\begin{tabular}{c|c|c|c|c|c}
\hline & & & \multicolumn{2}{|c|}{ Diagnosis } & \multirow{2}{*}{ Year } \\
\cline { 4 - 6 } & Total & $\begin{array}{c}\text { Birth cohort } \\
1911-1925\end{array}$ & $\begin{array}{c}\text { Before start } \\
\text { of project }\end{array}$ & $\begin{array}{c}\text { After start } \\
\text { of project }\end{array}$ & Misclassified \\
\hline 1973 & 50 & 19 & $\ldots$ & $\ldots$ & $\ldots$ \\
1974 & 53 & 17 & $\ldots$ & $\ldots$ & $\ldots$ \\
1975 & 61 & 23 & 22 & 1 & 0 \\
1976 & 59 & 20 & 14 & 2 & 4 \\
1977 & 51 & 16 & 11 & 5 & 0 \\
1978 & 64 & 14 & 8 & 4 & 2 \\
1979 & 64 & 19 & 8 & 10 & $1 \neq$ \\
1980 & 62 & 21 & 5 & 13 & 3 \\
1981 & 68 & 16 & 5 & 11 & 0 \\
\hline
\end{tabular}

* For example, stomach cancer unclassified as breast cancer. The Dutch words for breast and stomach are very similar and when handwritten may be misleading.

+Division not applicable.

\#iagnosis not confirmed. 
RESULTS

Of the 46 cases $9(20 \%)$ had been screened in the restricted period; 59 of the 138 controls ( $43 \%$ ) had been screened during this period. The percentage screened among the controls over the whole period (1975-80) versus the restricted period was $67 \%$, which is a similar percentage response to that $(72 \%)$ reported previously for screening in the total population. ${ }^{2}$ Table II gives the distribution of screening in the matched case-control groups. Cases dying of breast cancer and controls were compared by whether they had been screened in the restricted period. The relative risk of dying of breast cancer among women ever screened compared with women never screened was $0.30\left(\chi^{2}=7 \cdot 64, p=0.003\right.$, one sided; $95 \%$ confidence interval $0 \cdot 13-0 \cdot 70) .{ }^{7}$ Stratification by birth cohort or age (table III) gave a trend towards lower odds ratios for older birth cohorts and for higher ages. No effect of screening could be discerned in the age group 50-54. For the analysis of the number of screening examinations the matching was ignored. There was a significant trend $(p<0 \cdot 05)^{7}$ towards lower odds ratios for higher numbers of screening examinations (table IV).

The hypothesis of a favourable effect of screening is further supported by trends in birth-cohort-specific breast cancer mortality rates. The figure shows the mortality rates grouped in periods of 2 years, in the period 1973-81 for the three 5 -year birth cohorts at which screening was aimed and the three 5-year birth cohorts born in the years 1896-1910. The expected increase in mortality with time (due to ageing) is

TABLE II-DISTRIBLTION OF SCREENING IN CASE-CONTROL COMBINATIONS

\begin{tabular}{l|c|c|c|c|c}
\hline \multirow{2}{*}{\multicolumn{1}{c|}{ Case }} & \multicolumn{3}{|c|}{ Number of matched controls screened } & \multirow{2}{*}{ Total } \\
\cline { 2 - 5 } & 0 & 1 & 2 & 3 & 9 \\
\hline Screened & 1 & 4 & 3 & 1 & 9 \\
Not screened & 11 & 10 & 12 & 4 & 37 \\
\hline
\end{tabular}

Odds ratio $=\frac{(1 \times 3)+(4 \times 2)+(3 \times 1)}{(10 \times 1)+(12 \times 2)+(4 \times 3)}=\frac{14}{46}=0.30$

TABLE III-ODDS RATIOS STRATIFIED BY BIRTH COHORT AND BY AGE AT DIAGNOSIS

\begin{tabular}{|c|c|c|}
\hline- & Odds ratio & $\begin{array}{l}\text { Number of } \\
\text { matched } \\
\text { combinations }\end{array}$ \\
\hline \multicolumn{3}{|l|}{ Birth cohort } \\
\hline $1921-1925$ & 0.82 & 12 \\
\hline $1916-1920$ & $0 \cdot 31$ & 14 \\
\hline $1911-1915$ & 0.05 & 20 \\
\hline \multicolumn{3}{|l|}{ Age at diagnosis } \\
\hline $50-54$ & $1 \cdot 13$ & 10 \\
\hline $55-59$ & $0 \cdot 31$ & 12 \\
\hline $60-64$ & 0 & 17 \\
\hline $65-69$ & $0 \cdot 10$ & 7 \\
\hline
\end{tabular}

TABLE IV-INFLUENCE OF NUMBER OF SCREENING EXAMINATIONS ON ODDS RATIOS

\begin{tabular}{l|c|c|c|c|c} 
& \multicolumn{4}{|c|}{ Number of screens } & \multirow{2}{*}{ Total } \\
\cline { 2 - 5 } \multicolumn{1}{c|}{-} & 0 & 1 & 2 & 3 & 46 \\
Case & 37 & $5^{\star}$ & $1+$ & $3 \neq$ & 46 \\
Control & 79 & 28 & 23 & 8 & 138 \\
Odds rat10 & 1.00 & 0.41 & 0.09 & 0.80 & 0.30 \\
\hline
\end{tabular}

* 4 detected at first screen; years of birth $1917,1922,1922,1923.1$ after noncompliance at second screen, 32 months after first screen, year of birth 1925 . $\dagger 1$ detected at second screen, year of birth 1924 .

$\$ 3$ interval cancers, 9,10 and 14 months after third screen, years of birth 1912 , 1917,1920 .

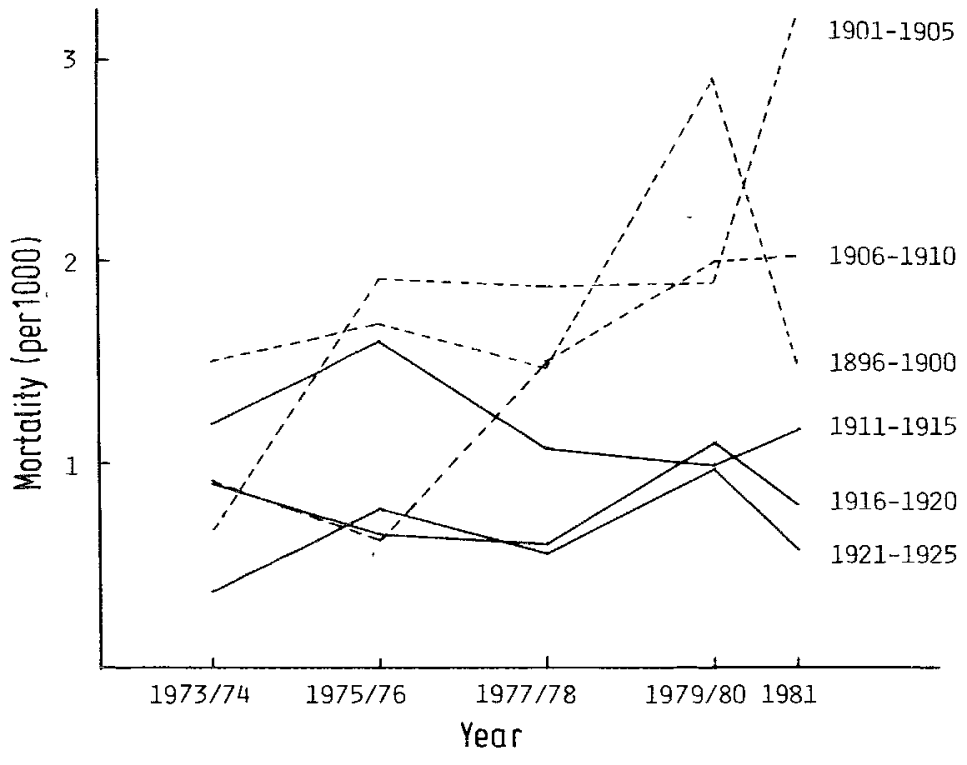

Breast cancer mortality rates for 5 -year birth cohorts in Utrecht, $1973-1981$.

seen for the older three cohorts, but not for the younger three cohorts, among whom mortality did not change. $43 \%$ of the controls had been screened in the restricted period, suggesting that with a relative risk among the ever-screened of $0 \cdot 30$, the mortality among the cohorts at whom screening was aimed should be $70 \%$ of the expected $(0 \cdot 57+0 \cdot 43 \times 0 \cdot 30)$. Given 46 observed deaths, 66 deaths might have been expected. The addition of 20 extra deaths would make the mortality curves for the screened cohorts parallel to those of the unscreened cohorts in the figure. Since the deaths that might have been prevented up to now represent a small proportion $(13 \%=20 /$ $[20+46+73+10])$ of deaths in the cohorts chosen for screening, with over half occurring in women diagnosed before screening started, we would expect little overall effect, as yet, on mortality. A reduction, if it is to occur, should become noticeable in 1981-85.

\section{DISCUSSION}

The success of a screening programme depends on the accuracy of the screening procedure, diagnosis, and the percentage of subjects attending, and also on detection of endpoints, such as the presence and stage of lesions and casemortality. Such results can be readily evaluated. In the DOM project they proved to be attainable goals. ${ }^{2}$ However, the results are only suggestive of long-term benefits. ${ }^{8}$ The best measure in cancer screening programmes is a comparison of the mortality rates in a randomised trial. Such a comparison was deemed impracticable in the DOM project, but evaluation was carried out in a non-experimental way. ${ }^{2}$ Screening appears to give protection against dying from breast cancer, especially for elderly women and women who have been screened twice (the number of women screened three times in this study is very small). However, we must consider the possibility that we have overlooked biasing factors. Differences in death rate between those who attended for screening and those who did not should be investigated. Any effect of age was eliminated by matching, but a high incidence of breast cancer could lead to higher mortality. However, the incidence of breast cancer in unscreened women was the same as that in the population before screening. The stage of the disease at diagnosis affects the prognosis and, thus, mortality. In the unscreened group cancer tended to be detected at a later stage than in the 
screened group. Since this was the purpose of the programme, stage cannot confound the results. The stage distribution in the unscreened group, however, was almost identical to that in the general population before screening started. ${ }^{2}$ Therefore the unscreened women seem not to be a group with particularly poor prognosis. Nevertheless, we are investigating the possibility that the unscreened cases had unusually low survival. Any prognostic factor other than stage differing in prevalence between the screened and unscreened women could confound the results. At present no such factor has been identified. Furthermore, during 1975-80 there was no specific therapy in Utrecht which could have affected breast cancer mortality. Screening, therefore, either protects against death from breast cancer or postpones death. If the latter suggestion is correct, one would expect a gradual change in odds ratio to unity over time.

We thank the Central Bureau for Statıstics, the local authorities, and the cancer registry of the DOM-project, for their help in collecting the data; and
Dr Peter Hill, for his comments. This study was funded by the Praeventiefonds.

Correspondence should be addressed to H. J. A. C., Preventicon, Radboudkwartier $261-263,3511$ CK Utrecht, The Netherlands.

\section{REFERENCES}

I Shapiro $\mathrm{S}$, Strax $\mathrm{Ph}$, Venet $\mathrm{L}$. Periodic breast cancer screening in reducing mortality from breast cancer. $7 A M A$ 1971, 215: 1777-85.

2. Waard F de, Collette HJA, Rombach JJ, Baanders-van Halewun EA, Honing C. The DOM-project for the early detection of breast cancer, Utrecht, The Netherlands. $\mathscr{f}$ Chron Dis 1984; 37: 1-44.

3. Clarke EA, Anderson TW. Does screening by "Pap" smears help prevent cervical Cancer? Lancet 1979, 11 1-4.

4 Gordis L Should dead cases be matched to death controls? Am 7 Eptdemol 1982; 115: $1-5$.

5. Morrison AS Case defintion in case-control studies of the efficacy of screening. Am $\mathfrak{f}$ Epidemol 1982; 115: 6-8.

6. Weiss NS. Control definition in case-control studies of the efficacy of screenng and dıagnostıc testıng. Am $\mathcal{F}$ Epldemiol 1983; 118: 457-60.

7. Breslow NE, Day NE. The analysis of case-control studies In. Davies W, ed. Statistical methods in cancer research. IARC Scientific publication no 32. Lyon: IARC, 1980 162-89

8 Cole Ph, Morrison AS. Basic issues in cancer screening. In: Miller AB, ed. Screening in cancer UICC Technical Report Series, vol 40. Geneva: UICC, 1978: 7-39.

\section{Occasional Survey}

\section{CONGENITAL ABNORMALITIES IN LEGAL ABORTIONS AT 20 WEEKS' GESTATION OR LATER}

\section{EVA ALBERMAN \\ ROSALIND STANWELL-SMITH}

London Hospital Medical College, Turner Street, London E1 $2 A D$

\begin{abstract}
Summary A study of late abortions by the Royal
College of Obstetricians and Gynaecologists made possible estimation of the number of abortions carried out for various types of confirmed congenital defects at or after 20 completed weeks of gestation. A reduction in the legal age of fetal viability to 24 weeks, in the absence of any other change in practice, would have stopped an estimated 26 abortions for confirmed serious fetal defects other than anencephaly in 1982; a reduction to 22 weeks would have stopped 77 such abortions.
\end{abstract}

\section{INTRODUCTION}

LOWERING the gestational age at which a fetus is legally deemed to be viable would affect the possibility of aborting fetuses diagnosed in late pregnancy as having a congenital abnormality. " Some idea of the size of this effect can be obtained from a study of late abortions carried out in England and Wales in the first half of $1982 .^{2}$ This study gave an opportunity to investigate the types of defect found in fetuses aborted legally at 20 weeks' gestation or later and also the diagnostic procedures used.

\section{METHODS}

A detailed description of the methods used to obtain the sample has been published elsewhere. ${ }^{2}$ Special permission was given by the chief medical officers of England and Wales to sample and abstract data from the notifications of legal abortions returned to them between Aug 3, 1981, and July 31, 1982. Included in this sample were all abortions notified as having been carried out at 20 weeks' gestation or later. These data provided background information for our study and the possibility of validating information obtained by the study team with that analysed by the Office of Population Censuses and Surveys while retaining strict regard for confidentiality.
A questionnaire was sent to the notifying doctors, asking for more details about gestational age, whether a congenital abnormality had been suspected or confirmed, and dates and types of any prenatal diagnostic tests for the sample notified between Jan 1 and June 6 , 1982, of abortions carried out in residents of the UK.

\section{RESULTS}

1080 abortions were notified as having been carried out at 20 or more weeks of gestation to residents of the UK in the first 6 months of 1982 . For $973(90 \%)$ cases the notifying doctor returned a questionnaire with more clinical details than were available on the notification. In 175 of the latter $(18 \%)$ the grounds for abortion were, or included, a substantial risk of handicap (ground 4), a proportion very close to that for which ground 4 was mentioned in the very

TABLE I-ABNORMALITIES AS DESCRIBED IN 166 ABORTIONS OF 20 WEEKS' OR MORE GESTATIONAL AGE

\begin{tabular}{l|c}
\hline \multicolumn{1}{c|}{ Abnormality } & $\mathrm{n}$ \\
\hline Central nervous system & \\
Anencephaly + spina bifidat & 41 \\
Spina bifida without anencephaly & 43 \\
Hydrocephalus without spina bifida & 8 \\
Total & 92 \\
Chromosomal defects & \\
Down syndrome & 24 \\
Other autosomal trisomy & 7 \\
Sex chromosome anomaly & 9 \\
Other & 6 \\
Total & 46 \\
Single gene defects & \\
Sandhoff's disease & 1 \\
Gangliosidosis & 1 \\
Thalassaemia major & 2 \\
Osteogenesis imperfecta & 1 \\
Duchenne muscular dystrophy & 2 \\
Alpha-l-antitrypsin deficiency & 1 \\
Total & 9 \\
Other & \\
Dandy-Walker syndrome & 1 \\
Cleidocranial dysostosis & 1 \\
Sacrococcygeal teratoma & 1 \\
Potter's syndrome & 1 \\
Albinism & 1 \\
Pulmonary defect & 1 \\
Exomphalos & 5 \\
Multiple & \\
Not known & \\
\hline & \\
\hline & \\
\hline & \\
\hline
\end{tabular}

*Includes 3 with chromosomal defects also.

tIncludes encephalocele.

†ncludes Meckel's syndrome 